\title{
Review
}

\section{What Is Sensitive Skin? A Systematic Literature Review of Objective Measurements}

\author{
Renée Richters $^{\mathrm{a}} \quad$ Denise Falcone $^{\mathrm{a}} \quad$ Natallia Uzunbajakava ${ }^{\mathrm{b}} \quad$ Willem Verkruysse $^{\mathrm{b}}$ \\ Piet van Erp ${ }^{a}$ Peter van de Kerkhof ${ }^{a}$

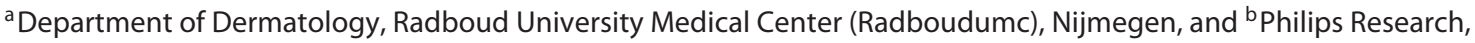 \\ Eindhoven, The Netherlands
}

\section{Key Words}

Sensitive skin · Biophysical measurements .

Multifactorial questionnaires

\begin{abstract}
Despite sensitive skin being highly prevalent, no consensus on the definition and pathomechanism of sensitive skin exists. Here we report the results of a systematic literature review of diagnostic methods for sensitive skin at clinical, histological and biophysical levels. A systematic search revealed 27 out of 1,701 articles which we appraised in detail. Impaired skin barrier function and increased vascular reactivity are most often associated with sensitive skin. We identified key reasons causing an ambiguity around the sensitive skin phenomenon. We propose using standardized selection methods of subjects by a multifactorial questionnaire spanning a range of provocations, including those of chemical, mechanical and environmental origin, followed by clinical, histological and top-notch biophysical measurements. This could lead to a breakthrough in the understanding of the sensitive skin phenomenon, fueling advances of biomedical and dermatological science.

(c) 2014 S. Karger AG, Basel
\end{abstract}

(C) 2014 S. Karger AG, Base

$1660-5527 / 14 / 0282-0075 \$ 39.50 / 0$

\section{Introduction}

In the previous century, sensitive skin was rarely reported in the scientific literature and its existence was questioned by biomedical scientists. Various imprecisely defined terms have been proposed to characterize susceptible skin, emphasizing its heterogeneous presentation, and only few research groups have focused on objective approaches to identify differences in sensitive skin [1-10].

In the past years, the view on sensitive skin has changed dramatically. Large epidemiological studies on the prevalence of sensitive skin have been conducted, concluding that the percentage of self-reported sensitive skin is as high as $50-61 \%$ among women [11-15] and $30-44 \%$ among men [11-14]. Since the prevalence of sensitive skin proves to be high across industrialized countries and to have considerable impact on quality of life [16], unraveling clinical, biophysical and histological characteristics of sensitive skin has become a significant topic of research for cosmetic and pharmaceutical industries and for biomedical researchers.

People classifying themselves as having sensitive skin perceive skin discomfort, particularly characterized by stinging, burning or itching sensations [16-18]. Remark-

\section{KARGER 125}

E-Mail karger@karger.com www.karger.com/spp
R.J.H. Richters, MD

Radboudumc, René Descartesdreef 1 Internal postal code 370, PO Box 9101 NL-6500 HB Nijmegen (The Netherlands)

E-Mail renee.richters@ radboudumc.nl 
ably, visible signs of skin irritation are frequently absent $[14,17-20]$. To define the symptom profile and to address exogenous and endogenous factors which may elicit skin reactions, nonuniform questionnaires have been conducted in different populations [12-14]. Furthermore, various chemical and electrical provocations followed by noninvasive measurements of biophysical parameters of the skin have been widely appraised in persons having sensitive skin perceptions to quantify sensory irritation and to reveal the underlying mechanisms of sensitive skin $[9,19,21-23]$. Various exogenous factors such as cosmetic ingredients and environmental conditions have been indicated to trigger sensitive skin reactions. Many provocations used in experiments resulted in sensory skin reactions $[19,21,22,24]$. However, susceptibility to one provocative agent does not predict susceptibility to another [25-28].

Despite extensive research, a consensus on the definition of sensitive skin has not been reached and attempts to develop a valid diagnostic test to objectively identify the complete profile of sensitive skin have failed. Factors that impede the detection of sensitive skin are the heterogeneity of symptoms [17], the subjectivity of sensory discomfort [29] and the absence of visible clinical features $[17,21]$. Updates have been published recently, but a systematic approach and a critical appraisal of published studies is still lacking $[19,22,30,31]$.

\section{Objectives}

The aim of this review is to shape a different perspective on research in the area of sensitive skin by relating perceptions, quantitative sensory measurements and objective biophysical and morphological aspects of this phenomenon. We include the following objectives:

(1) to create an overview of the morphological, physiological and biophysical characteristics of sensitive skin;

(2) to critically appraise the quality and reliability of diagnostic tests for sensitive skin;

(3) to identify gaps in the knowledge of sensitive skin;

(4) to formulate recommendations for future research directions.

This systematic review may be particularly interesting both for innovators working in the area of skin irritation research and experimental dermatology, who aspire to look beyond the solely cosmetic perspective and embrace objective measurements of sensitive skin, and clinicians, who are seeking evidence on the pathomechanical background of sensitive skin to address solutions for individual differences in skin reactions.

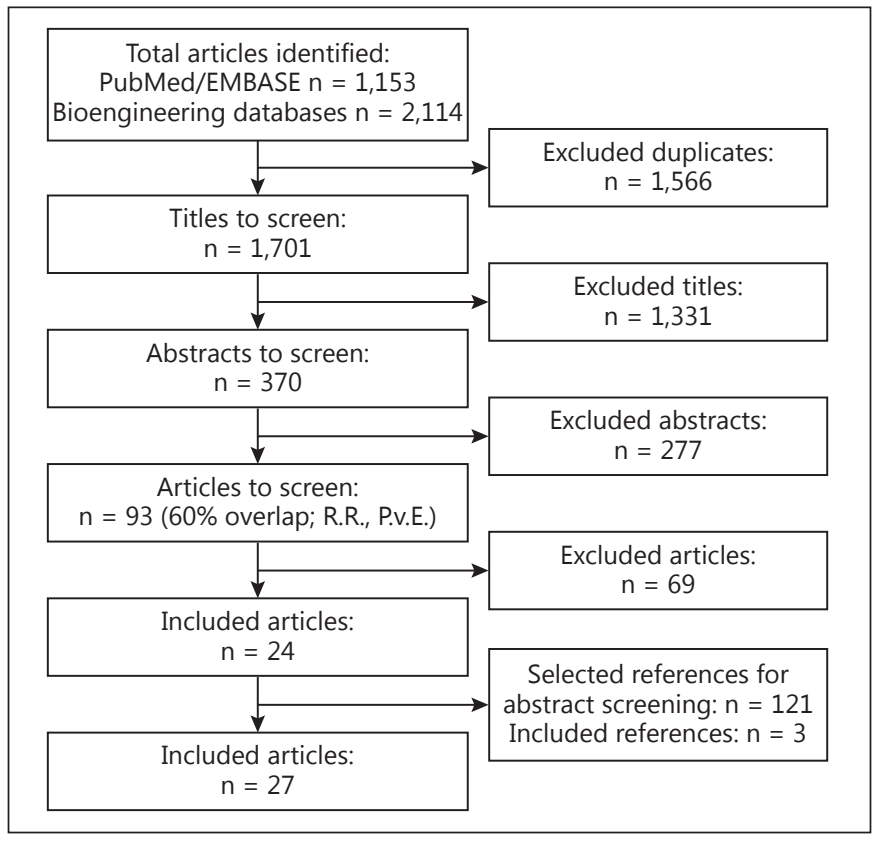

Fig. 1. Article selection process.

\section{Materials and Methods}

To collect data on sensitive skin, an extensive literature search was performed for articles published from January 2000 to July 2012 in the following electronic bibliographic indexes: PubMed, EMBASE, BIOSIS, KOSMET, PASCAL, LIFESCI, HCAplus, Inspec and Compendex (online suppl. table S1; for all online suppl. material, see www. karger.com/doi/10.1159/000363149). The path towards an understanding of sensitive skin was paved by several research groups previously and served as a basis to trigger a new generation of experimental studies after 2000. The first search strategy contained all possible synonyms for sensitive skin: 'sensitive', 'sensitivity', 'hypersensitive', 'hyperreactive', 'irritation', 'irritated', 'susceptibility', 'sensibility', 'intolerance', and 'cutaneous sensitivity'. The second search strategy contained specific and general terms on diagnostics and physiology. Third, symptoms and sensations were included, being the phenomenon of sensitive skin based on perceptions. The three searches were crossed and restricted to publications on humans, English language and articles which were published after January 1, 2000.

\section{Study Selection Criteria}

A total of 3,267 citations were identified by the search strategy. Duplicate citations were removed. Relevant articles were selected by a four-stage process (fig. 1). First, a selection of 1,701 articles (R.R.) was made using a checklist containing four items: descriptions of definition, epidemiology, demography (e.g. age, gender, ethnicity, skin type), and diagnostics on sensitive skin and skin irritation. The presence of at least one of these items was mandatory for an article to be included in the next steps of the analysis. Second, abstracts of selected titles were assessed independently by two reviewers (R.R. and P.v.E.) using a more detailed checklist to select articles considered to be relevant. The main reason for exclusion 
was when testing the irritation potential of substances was addressed or when perceptions of individuals were lacking. Consensus was reached by discussion on inclusion; 93 abstracts were eligible for detailed full-text assessment.

\section{Article Screening}

After critical assessment of full texts in the third stage, 24 articles were included. The main reason for exclusion was the absence of descriptions or evaluation of perceptions of sensitive skin, e.g. burning feeling, stinging feeling, discomfort, etc. Finally, to ensure that all relevant studies were included, reference lists of literature reviews and included full-text articles were additionally scanned, resulting in the inclusion of 3 articles.

Quality Assessment

The STROBE method (Strengthening the Reporting of Observational Studies in Epidemiology) was used in the assessment of the quality of studies as this tool comprises a level of evidence determination according to the study design of observational studies [32]. Each study received a score of $0-22$, expressed as a percentage of the maximum score, by two independent reviewers (D.F. and R.R.), relating to three grades of recommendation based on the fulfillment of quality criteria. When scores differed by more than 1.5 , consensus was reached by discussion. Quality assessment and data extraction tables are included in online supplementary table S2.

\section{Results}

\section{Article Quality}

Overall, 5 articles were classified in category C (score $<60 \%$ ) and the remaining 22 articles were classified in category B (score 60-80\%). The mean score of the articles was $63.4 \pm 5.6 \%$. Shortcomings mainly refer to (1) poor or absent explanation of the choice of study design and population size, (2) addressing bias and limitations of the study and (3) indication of the number of participants included at each stage.

\section{Definition of Sensitive Skin}

Our review confirmed that there is no consensus on the definition and the symptom profile of sensitive skin. The condition has been characterized by solely neurosensory discomfort in 8 studies, while 9 studies suggest that these perceptions may be accompanied by visible skin irritation such as erythema and dryness.

\section{Study Sample Characteristics}

All studies included are observational studies in adults. The majority $(\mathrm{n}=16)$ included both sexes, nearly all with a higher proportion of women $(n=13)$. Out of 20 studies that appointed the mean age of subjects, 14 addressed a mean age between 25 and 40 years. A total of 8 studies addressed the ethnicity of subjects: 5 studies included Cau- casian subjects, 3 included Asian subjects; 1 study compared these two skin types. Studies comparing a predetermined population with sensitive skin with a control group included small groups (4-36 subjects). The most frequently investigated body sites were the nasolabial fold $(\mathrm{n}=12)$, the volar forearm $(\mathrm{n}=10)$, the cheek $(\mathrm{n}=5)$, other facial areas $(n=6)$, and the hands $(n=4)$.

\section{Sensory Hyperreactivity}

Population Selection Methods. Different methods are applied to enable the assessment of sensitive skin behavior, including provocations with chemical substances and selection by self-reported perceptions obtained by questionnaire. Studies addressing individual differences in skin reactions elicited sensations by different agents: lactic acid (LA), sodium lauryl sulfate (SLS) and various other topical agents such as capsaicin, menthol, benzoic acid, transcinnamic acid, octane, cumene, methyl nicotinate and acetyl-b-methylcholine chloride (vasodilators), ethanol, allergens, occlusion, cocamidopropyl betaine and benzalkonium chloride (surfactants), and balsam of Peru; 1 study selected subjects by determining the current perception threshold in the neck [33] and 12 studies selected subjects based on self-assessment by questionnaire.

The lactic acid stinging test (LAST), first developed to appraise the stinging capacity of topically applied substances [34], is proposed as the best predictor available for sensitive skin and is widely used to select volunteers for clinical studies [3]. We also confirm that the LAST identifies 'stingers' - subjects perceiving stinging sensations when LA is applied on the nasolabial fold - assuming to correspond to sensitive skin and was most frequently used to categorize subjects on skin sensitivity $(n=9)$. A detailed evaluation of the articles included in this review reveals that, in sensitive skin, the time to onset of stinging and time to peak are shorter, higher peak amplitudes are observed [35] and mean overall stinging scores are higher in response to LA $[36,37]$. However, the test lacks objectivity, sensitivity and specificity for sensitive skin. In fact, 59.9\% [15] and 64\% [35] of subjects with self-reported sensitive skin report a positive reaction to the LAST. A study by Cho et al. [38] found that $80 \%$ of sensitive subjects report stinging following the LAST. However, $66.7 \%$ of nonsensitive subjects also experience this reaction. Moreover, several studies have shown that sensitivity to one substance seems not to predict sensitivity to another $[28,35,39]$, questioning the validity of the LAST as a reliable diagnostic test for sensitive skin.

Only 2 studies using the LAST as an indicator of sensitive skin found significant differences in biophysical measurements in stingers, namely, a higher transepidermal 
water loss (TEWL) on the nasolabial fold $(\mathrm{p}=0.03)$ and on the right $(p=0.05)$ and left cheek $(p=0.03)[40,41]$. Important to note here is that Distante et al. [41] (2002) included subjects who also met the criteria of self-reported sensitive skin and who had specific skin reactions besides a positive LAST. Differences in skin reactions could barely be enhanced by physical irritants such as SLS [42]. In the past, the enhancement of differences in skin reactions between stingers and nonstingers also failed [25, 27]. In 2011, Schliemann et al. [51] observed that after only 5 days stingers showed significantly higher skin irritation following repetitive cumene and octane application. However, differences in biophysical measurements do not ensure differences in skin sensitivity since these parameters have high interindividual variability in the general population.

As stated earlier, besides the LAST, 12 studies selected sensitive and nonsensitive skin subjects using either extended nonuniform questionnaires, including sensory perceptions, visible symptoms and environmental and endogenous factors, or asking whether an individual had sensitive skin or not. In particular, 1 study used a labeled magnitude scale permitting both semantic descriptors and a continuum of intensity rankings to compare individuals [43].

When sensitive and nonsensitive subjects were selected by questionnaire, few studies found significant differences in biophysical parameters between sensitive and nonsensitive subjects. An inverse correlation was shown between the detection thresholds of capsaicin and sensitive skin indexed by questionnaire [44], suggesting that these methods could be more specific than the LAST in detecting sensitive skin. It is known that whenever skin is challenged by capsaicin, noxious heat or low $\mathrm{pH}$, transient receptor potential vanilloid 1 (TRPV1) is activated $[45,46]$, resulting in nociceptor-mediated burning pain. An overexpression of this ion channel could play a key role in the pathophysiology of sensitive skin, as its inhibition results in reduced burning sensation following capsaicin application [47]. Differences in pain perceptions were also observed in subjects with sensitive skin by fMRI. Subjects with sensitive skin indexed by questionnaire showed activity in both hemispheres when stimulated with LA on the right nasolabial fold, whereas only the left primary sensorimotor area was active in subjects with nonsensitive skin [36].

\section{Impaired Barrier Function}

Transepidermal Water Loss. In total, 11 studies focused on TEWL as a parameter of skin barrier function (table 1). Most studies observed higher TEWL in the unchallenged skin of subjects with sensitive skin compared to those with nonsensitive skin $[20,41,48,49]$ and in stingers compared to nonstingers [39-41, 50, 51], while only 2 studies identified significantly higher TEWL in sensitive skin $[40,41]$. Moreover, higher TEWL at baseline seems to correlate with a stronger TEWL increase following provocation [40]: plastic occlusion resulted in a significantly longer evaporation half-life time in subjects with sensitive skin [49], and a trend to increased recovery time of TEWL following SLS stimulation was also observed [20]. A stronger increase of TEWL was also found following SLS provocation both in sensitive versus nonsensitive atopic skin [52] and in a population of Japanese versus German women [53]. The latter finding is particularly interesting as in general Asian women often report sensitive skin.

Stratum Corneum Hydration. Overall, 10 studies presented data on hydration of the stratum corneum (measured through capacitance, CAP) in sensitive skin (table 1). A significantly lower CAP at facial areas in subjects with sensitive skin [37] and in stingers [40] and a nonsignificantly lower CAP at facial areas in subjects with sensitive skin were found [41]. Challenging the skin with octane or cumene, however, resulted in a significantly lower CAP in stingers compared to nonstingers [51]. A lower CAP at baseline predicted earlier onset of stinging and a weak correlation (Spearman's test: $\mathrm{r}=0.307, \mathrm{p}=$ 0.03 ), with a higher clinical stinging score identified [39]. On the other hand, other studies found no difference in CAP between stingers and nonstingers $[40,50,51]$ or between subjects with sensitive and nonsensitive skin [20, $48]$, either challenged or unchallenged $[20,48,51]$. The lower CAP is consistent with findings of a clinically dryer skin [15] and a lower facial ceramide content of the stratum corneum found in subjects with sensitive skin ( $\mathrm{p}=$ 0.037 ) [38]. This implies that an impaired skin barrier and a dryer skin underlie sensitive skin.

Sebum and $p H$. Previously, a study reported a significantly lower sebum level in subjects with sensitive skin [9]. In studies evaluated in this review, clinically less oily $(\mathrm{p}<0.01)$ skin was detected in subjects with sensitive skin [37]. However, objective surface sebum measurements show no differences between subjects with sensitive and nonsensitive skin $[37,54]$ and between stingers and nonstingers [40]. It is remarkable that Asian people, who more often report sensitive skin $[53,55]$, have a clinically more oily skin compared to Caucasians (31.9 vs. 24.0\%). Aramaki et al. [53] (2002) detected differences in sebum secretion levels between Japanese and Caucasian women following SLS provocation. This indicates that Japanese skin could be more
78

Skin Pharmacol Physiol 2015;28:75-83 DOI: $10.1159 / 000363149$
Richters/Falcone/Uzunbajakava/ Verkruysse/van Erp/van de Kerkhof 
Table 1. CAP and TEWL in subjects with sensitive versus nonsensitive skin

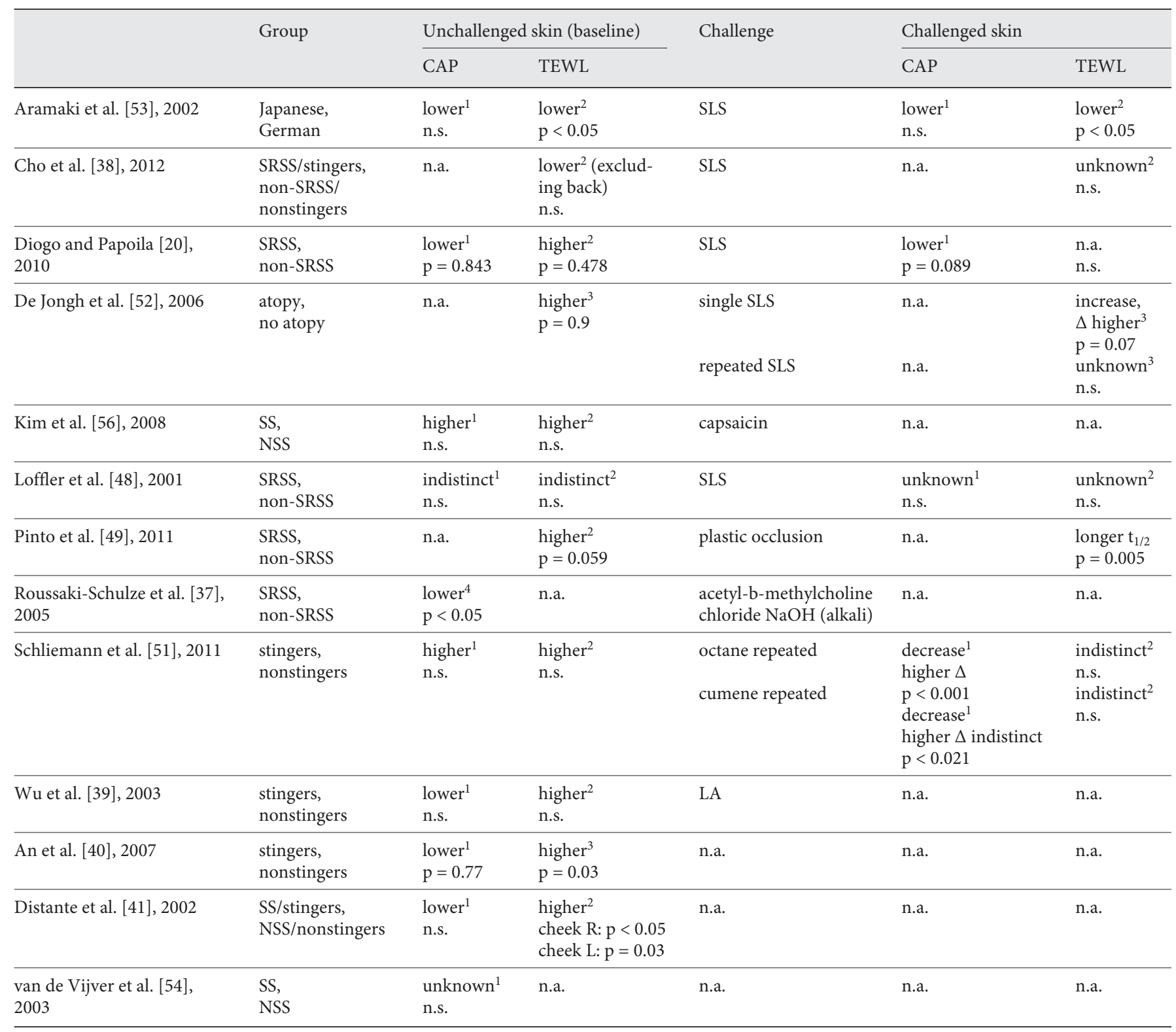

CAP = Capacitance (stratum corneum hydration); n.s. = nonsignificant difference; SRSS = self-reported sensitive skin; n.a. $=$ not applicable; SS = sensitive skin; NSS = nonsensitive skin. Significant $\mathrm{p}<0.05$.

${ }^{1}$ Measured by Corneometer, C+K Electronics. ${ }^{2}$ Measured by TEWAmeter, C+K Electronics. ${ }^{3}$ Measured by VaporMeter, Delfin. ${ }^{4}$ Ionto-Skin-Diagnose, Ionto Comed $\mathrm{GmbH}$.

susceptible to chemical irritation, possibly due to alterations in sebum secretion levels. The literature is inconclusive with regard to the role of sebum secretion in sensitive skin perceptions.

Recent studies show no significant differences in skin surface $\mathrm{pH}$ for subjects with sensitive skin $[37,54]$ and stingers [40], while previous studies reported significantly higher baseline $\mathrm{pH}$ in subjects with sensitive skin [9] and a significantly stronger increase of $\mathrm{pH}$ at $25 \mathrm{~min}$ after stimulus among stingers compared to nonstingers [4]. Skincare products of $\mathrm{pH} 8$ affect the impact of SLS, as evidenced by a significant increase of TEWL [56]. It seems reasonable to conclude that there is an impaired barrier function, allowing faster penetration of LA and therefore a faster increase of surface $\mathrm{pH}$ after LA [4], enhancing sensitivity to chemical agents [56]. 
Skin Structure and Viscoelasticity. The skin of stingers with self-reported sensitive skin appears to be rougher since fast Fourier transform evaluation of tapes after tapestripping the stratum corneum in 243 stingers revealed a lower content of cells. This implies a more irregular and rougher [57], possibly less hydrated, skin. However, objectively measured skin elasticity and distensibility show no correlation with hypersensitivity [54].

Based on these results, we suggest that an impaired skin barrier function plays a role in the pathomechanism of sensitive skin and needs to be investigated in depth.

\section{Inflammatory or Vascular Response}

Individuals with sensitive skin frequently report reddening of their skin $[15,35,37,38,43,44,49,57,58]$. Therefore, the assessment of erythema in skin irritation has been widely investigated, either by visual assessment [28, 37, 41, $59,60]$ or by quantitative methods such as tristimulus reflectance colorimetry ( $\mathrm{a}^{*}$ value) $[20,50-52]$, reflectance spectrophotometry (erythema index) $[38,53,59]$ or laser Doppler flowmetry (cutaneous blood flow) [20, 41, 48, 50, $51,53,61]$. Increased vascular reactivity has been emphasized in the literature as a key player in sensitive skin pathophysiology. In this review, lower objective values for redness were found at baseline: lower a* values in subjects with sensitive skin $[20,50,53]$ and lower erythema index and cutaneous blood flow in stingers $[38,41,50,51]$ and subjects with sensitive skin $[20,38,48]$ were observed (table 2 ). Inconclusive evidence was found with respect to enhanced vascular reactivity following provocations (table 2). The application of LA, SLS, capsaicin or cumene failed to enhance differences in erythema responses $[20,50,51,53]$, while the application of octane, acetyl-b-methylcholine chloride, allergen patch testing (European standard and cosmetics), and methyl nicotinate resulted in a stronger erythema response in stingers and in sensitive skin [37, 51]. Similar results on methyl nicotinate were found in 1991 [1]. Remarkably, 1 study observed a blanching reaction following methyl nicotinate solely in subjects with sensitive skin [37]. Japanese women demonstrate stronger vascular reactions compared to Caucasian women [53]. A proposed explanation for vascular reactivity in sensitive skin is a higher concentration of chemical agents absorbed in the skin, possibly implying an impaired barrier function, which could elicit vascular responses [62]. At a histological level, no differences with respect to endothelium markers were observed [33]. With regard to genetic characteristics, nonatopic subjects with a G-to-A transition (TNF-a polymorphism-308) have significantly higher stinging response following the LAST compared to nonatopic subjects with the wild type $(p=0.03)$, suggesting that TNF- $\alpha$ and an increase in NGF play a role in the perception of skin irritation [60].

\section{Allergic Predisposition}

Epidemiological studies support the association between sensitive skin and atopic diathesis due to a significantly higher individual manifestation of atopy in the sensitive skin group [14]. This indicates that impaired skin barrier function and increased mast cell degranulation could be involved in the pathophysiology. One of the included studies showed that atopic predisposition enhances erythema responses $(p=0.03)$ [52]. Although dermographism is comparable between subjects with sensitive and nonsensitive skin [37], histologically, increased numbers of CD117+ mast cells $(p<0.08)$ and a larger cross-sectional area of lymphatic vessels identified by LYVE-1 and podoplanin $(\mathrm{p}<0.001)$ were seen in individuals with a low current perception threshold [33]. Such differences in physiology are possibly responsible for the modulation of the perception threshold of nociceptive stimuli via the release of mast cell mediators. Total IgE in the blood does not differ [33].

\section{Discussion}

As sensitive skin is highly prevalent in the Western world, the understanding of the physiological reality of sensitive skin is of high importance. This systematic literature review concludes that potential causal pathways hypothesized to lead to a response pattern commonly designated as sensitive skin are the following: (1) sensory hyperreactivity, (2) impaired barrier function, (3) inflammatory or vascular responsiveness and (4) atopic predisposition.

This review also confirms that the identification of sensitive skin is complex. A single overall definition for sensitive skin is not supported by evidence and no objective diagnostic test has been found to be sensitive and reproducible. Strong evidence on pathways underlying sensitive skin is lacking. Only few provocative methods such as SLS, vasodilators and capsaicin possibly trigger the mechanism of sensitive skin, since these agents enhanced differences between subjects with sensitive and nonsensitive skin. The strongest evidence refers to an impaired skin barrier function. This impaired barrier may trigger both vascular hyperreactivity and sensory perceptions, suggesting different mechanisms according to different discomfort presentation.

The variety of tests, selection methods and measurement methods has potentially led to the large diversity of theories on the mechanism of sensitive skin. First, highly
80

Skin Pharmacol Physiol 2015;28:75-83 DOI: $10.1159 / 000363149$
Richters/Falcone/Uzunbajakava/ Verkruysse/van Erp/van de Kerkhof 
Table 2. a* values, erythema index and visual erythema assessment in subjects with sensitive versus nonsensitive skin

\begin{tabular}{|c|c|c|c|c|c|c|}
\hline & \multirow[t]{2}{*}{ Group } & \multicolumn{2}{|c|}{ Unchallenged skin (baseline) } & \multirow[t]{2}{*}{ Challenge } & \multicolumn{2}{|l|}{ Challenged skin } \\
\hline & & $a^{*}$ value & LDF & & $a^{*}$ value & LDF \\
\hline Aramaki et al. [53], 2002 & $\begin{array}{l}\text { Japanese, } \\
\text { German }\end{array}$ & $\begin{array}{l}\text { lower } \\
\text { n.s. }\end{array}$ & $\begin{array}{l}\text { lower } \\
\text { n.s. }\end{array}$ & $\begin{array}{l}\text { SLS } \\
\text { LA }\end{array}$ & $\begin{array}{l}\text { lower (n.s.) } \\
\text { higher }^{3}\end{array}$ & $\begin{array}{l}\text { lower (n.s.) } \\
\text { n.a. }\end{array}$ \\
\hline $\begin{array}{l}\text { Diogo and Papoila et al. } \\
{[20], 2010}\end{array}$ & $\begin{array}{l}\text { SRSS, } \\
\text { non-SRSS }\end{array}$ & $\begin{array}{l}\text { lower }{ }^{1} \\
\mathrm{p}=0.033\end{array}$ & $\begin{array}{l}\text { lower }^{2} \\
\mathrm{p}=0.143\end{array}$ & SLS & $\begin{array}{l}\text { higher }^{1} \\
\mathrm{p}=0.514\end{array}$ & $\begin{array}{l}\text { lower }^{2} \\
\mathrm{p}=0.178\end{array}$ \\
\hline Kim et al. [56], 2008 & $\begin{array}{l}\text { SS, } \\
\text { NSS }\end{array}$ & $\begin{array}{l}\text { lower }{ }^{1} \\
\text { n.s. }\end{array}$ & $\begin{array}{l}\text { similar } \\
\text { n.s. }\end{array}$ & capsaicin & n.a. & n.a. \\
\hline Loffler et al. [48], 2001 & $\begin{array}{l}\text { SRSS, } \\
\text { non-SRSS }\end{array}$ & n.a. & $\begin{array}{l}\text { indistinct }{ }^{2} \\
\text { n.s. }\end{array}$ & SLS & n.a. & $\begin{array}{l}\text { unknown }{ }^{2} \\
\text { n.s. }\end{array}$ \\
\hline $\begin{array}{l}\text { Schliemann et al. [51], } \\
2011\end{array}$ & $\begin{array}{l}\text { stingers, } \\
\text { nonstingers }\end{array}$ & $\begin{array}{l}\text { higher }{ }^{1} \\
\text { n.s. }\end{array}$ & $\begin{array}{l}\text { unknown } \\
\text { n.s. }\end{array}$ & $\begin{array}{l}\text { repeated octane } \\
\text { repeated cumene } \\
\text { single octane } \\
\text { single cumene }\end{array}$ & $\begin{array}{l}\text { higher }^{1} \text { day } 5 \\
\mathrm{p}=0.002 \text { higher }^{1} \\
\text { n.s.; n.a. } \\
\text { n.a. }\end{array}$ & $\begin{array}{l}\text { n.a. } \\
\text { n.a. } \\
\text { unknown }{ }^{4} \mathrm{p}=0.976 \\
\text { unknown }{ }^{4} \mathrm{p}=0.631\end{array}$ \\
\hline Distante et al. [41], 2002 & $\begin{array}{l}\text { SS/stingers, } \\
\text { NSS/nonstingers }\end{array}$ & n.a. & $\begin{array}{l}\text { higher }{ }^{2} \text { (exclud- } \\
\text { ing forehead) } \\
\text { n.s. }\end{array}$ & n.a. & n.a. & n.a. \\
\hline
\end{tabular}

Erythema index

Cho et al. [38], 2012

SRSS, non-SRSS/ indistinct ${ }^{5} \quad$ n.a.

n.a.

unknown $^{5}$

n.a.

stingers,

n.s.

n.s.

nonstingers

\begin{tabular}{|c|c|c|c|c|c|c|}
\hline $\begin{array}{l}\text { De Jongh et al. [52], } \\
2006\end{array}$ & $\begin{array}{l}\text { atopy, } \\
\text { no atopy }\end{array}$ & $\begin{array}{l}\text { higher }{ }^{5} \\
\text { n.a. }\end{array}$ & n.a. & SLS & $\begin{array}{l}\text { higher } \Delta^{5} \text { erythema } \\
\mathrm{p}<0.05\end{array}$ & n.a. \\
\hline $\begin{array}{l}\text { Visual erythema assessn } \\
\text { Roussaki-Schulze et al. } \\
\text { [37], } 2005\end{array}$ & $\begin{array}{l}t \\
\text { SRSS, } \\
\text { non-SRSS }\end{array}$ & n.a. & n.a. & $\begin{array}{l}\text { acetyl-b-methylcholine } \\
\text { chloride } \mathrm{NaOH} \text { (alkali) } \\
\text { European standard, } \\
\text { cosmetic patches }\end{array}$ & $\begin{array}{l}\text { higher } \mathrm{p}<0.01 \\
\text { higher } \mathrm{p}<0.05 \\
\text { higher } \mathrm{p}<0.05\end{array}$ & n.a. \\
\hline
\end{tabular}

LDF = Laser Doppler flowmetry; n.s. = nonsignificant difference; n.a. = not applicable; SRSS = self-reported sensitive skin; SS = sensitive skin; NSS = nonsensitive skin. Significant $\mathrm{p}<0.05$.

${ }^{1}$ Measured by Chromameter, Minolta. ${ }^{2}$ Measured by Peri Flux System, Perimed. ${ }^{3}$ Measured by Laser blood flow detector, Moor Instruments. ${ }^{4}$ Measured by Laser Doppler Imager, Moor Instruments. ${ }^{5}$ Measured by DermaSpectrometer, Cortex Technology.

heterogeneous methods to measure biophysical characteristics are applied following different provocations at different body sites in different moments in time in order to select subjects with sensitive skin. Even within the LAST method, various concentrations and inclusion criteria are used which are different from the original LAST [34]. Second, some studies did not set the required environmental conditions for biophysical measurements on TEWL and CAP, as recommended in the published guidelines [40]. Also, despite the assumption that various host factors such as allergic predisposition promote sensitive skin [21], many included studies did not take these potential confounders into consideration in selection processes, resulting in different populations, or did not report these confounders. Moreover, useful research data of the cosmetic industry is frequently kept confidential or published studies have methodological shortcomings and enrolled small subject groups, thus complicating the reliability and completeness of data on sensitive skin.

In order to unravel the pathomechanism and potential triggering pathways of this mechanism, first of all the symptom and perception profile associated with sensitive skin should be identified. A perception-based selection of subjects enables us to investigate the structural and physiological differences of sensitive skin compared to 'normal' skin. This selection could be more specific than the LAST.

Second, an important question is whether sensitive skin is a 'container term' comprising multiple pathways that elicit sensitivity. More specifically, and with relevance for clinical practice, is there a set of triggers that are able to predict a certain proclivity to having sensitive skin? Since 
sensitive skin seems not to be a one-dimensional condition, a more specific identification method for sensitive skin compared to provocations with LA or capsaicin may be a questionnaire or a scoring scale for neurosensory perceptions. A questionnaire enables the inclusion of a broader spectrum of triggers and common symptoms of sensitive skin and is applicable for clinical practice in order to predict one's propensity to experience sensitive skin.

We propose that selection methods with higher specificity such as subjective scoring scales could be adequate diagnostic tools to detect subjects with sensitive skin for research purposes and, when combined with consistent biophysical measurements, could possibly highlight significant differences in subjects with sensitive skin with respect to nonsensitive subjects and lead to consistent results. We propose using multifactorial questionnaires spanning a range of provocations, including those of chemical, mechanical and environmental origin, followed by clinical, histological and top-notch biophysical measurements. This could lead to a breakthrough in the understanding of the sensitive skin phenomenon, fueling the advances of biomedical and dermatological science. The next step could be to zoom in on the potential mechanisms involved with advanced techniques. For example, an extended analysis of the skin barrier structure and composition could provide new insights into the pathways involved in the development of the sensitive skin phenomenon.
Born out of clinical practice, it might be that sensitive skin plays a role in interindividual variability in reactivity potential among dermatological patients, as experienced in skin diseases such as psoriasis or acne $[6,63]$. This knowledge relates sensitive skin to knowledge on pathology in skin diseases and could be the basis for addressing solutions to differences in individual skin reactions in clinical practice. The ultimate goal of the identification of underlying mechanisms is to develop rational interventions for each individual with sensitive skin, implementing personalized medicine. For the future, we recommend using approaches focused on identifying the pathomechanisms causing perceptions of skin discomfort designated as sensitive skin to propose an evidencebased diagnosis and intervention for patients with sensitive skin.

\section{Disclosure Statement}

Prof. Dr. P. van de Kerkhof, the principal investigator of this study, has received reimbursement of the costs made to conduct this review from Philips Electronics Nederland B.V., acting through Philips Research. The authors affiliated to Philips Research are employees of Philips Research and have received a salary for this study. The authors affiliated to Radboudumc are employees of Radboudumc and have also received a salary for this study.

\section{References}

1 Berardesca E, Cespa M, Farinelli N, Rabbiosi G, Maibach H: In vivo transcutaneous penetration of nicotinates and sensitive skin. Contact Dermatitis 1991;25:35-38.

2 Berardesca E, Maibach HI: Sensitive and ethnic skin. A need for special skin-care agents? Dermatol Clin 1991;9:89-92.

3 Draelos ZD: Sensitive skin: Perceptions, evaluation, and treatment. Am J Contact Dermat 1997;8:67-78.

-4 Issachar N, Gall Y, Borell MT, Poelman MC: $\mathrm{pH}$ measurements during lactic acid stinging test in normal and sensitive skin. Contact Dermatitis 1997;36:152-155.

-5 Issachar N, Gall Y, Borrel MT, Poelman MC: Correlation between percutaneous penetration of methyl nicotinate and sensitive skin, using laser Doppler imaging. Contact Dermatitis 1998;39:182-186.

6 Mills OH Jr, Berger RS: Defining the susceptibility of acne-prone and sensitive skin populations to extrinsic factors. Dermatol Clin 1991;9:93-98.
7 Muizzuddin N, Marenus KD, Maes DH: Factors defining sensitive skin and its treatment. Am J Contact Dermat 1998;9:170-175.

-8 Paquet F, Piérard-Franchimont C, Fumal I, Goffin V, Paye M, Piérard GE: Sensitive skin at menopause; dew point and electrometric properties of the stratum corneum. Maturitas 1998;28:221-227.

-9 Seidenari S, Francomano M, Mantovani L: Baseline biophysical parameters in subjects with sensitive skin. Contact Dermatitis 1998; 38:311-315.

10 Simion AF, Rau AH: Sensitive skin: what is it and how to formulate for it. Cosmet Toiletries 1994;109:43s.

11 Farage MA: How do perceptions of sensitive skin differ at different anatomical sites? An epidemiological study. Clin Exp Dermatol 2009;34:e521-e530.

12 Guinot C, Malvy D, Mauger E, Ezzedine K, Latreille J, Ambroisine L, et al: Self-reported skin sensitivity in a general adult population in France: data of the SU.VI.MAX cohort. J
Eur Acad Dermatol Venereol 2006;20:380390.

13 Misery L, Myon E, Martin N, Verriere F, Nocera T, Taieb C: Sensitive skins in France: an epidemiological approach (in French). Ann Dermatol Venereol 2005;132:425-429.

14 Willis CM, Shaw S, De Lacharriere O, Baverel M, Reiche L, Jourdain R, et al: Sensitive skin: an epidemiological study. Br J Dermatol 2001; 145:258-263.

15 Sparavigna A, Di Pietro A, Setaro M: 'Healthy skin': significance and results of an Italian study on healthy population with particular regard to 'sensitive' skin. Int J Cosmet Sci 2005;27:327-331.

16 Misery L, Myon E, Martin N, Consoli S, Boussetta S, Nocera T, et al: Sensitive skin: psychological effects and seasonal changes. J Eur Acad Dermatol Venereol 2007;21:620-628.

17 Morizot F, Guinot C, Lopez J, LaFus I, Tschachler E: Sensitive skin: analysis of symptoms, perceived causes and possible mechanisms. Cosmet Toiletries 2000;115:83-89.
Richters/Falcone/Uzunbajakava/ Verkruysse/van Erp/van de Kerkhof 
18 Saint-Martory C, Roguedas-Contios AM, Sibaud V, Degouy A, Schmitt AM, Misery L: Sensitive skin is not limited to the face. Br J Dermatol 2008;158:130-133.

19 Primavera G, Berardesca E: Sensitive skin: mechanisms and diagnosis. Int J Cosmet Sci 2005;27:1-10.

20 Diogo L, Papoila AL: Is it possible to characterize objectively sensitive skin? Skin Res Technol 2010;16:30-37.

21 Farage MA, Katsarou A, Maibach HI: Sensory, clinical and physiological factors in sensitive skin: a review. Contact Dermatitis 2006; 55:1-14.

22 Farage MA, Maibach HI: Sensitive skin: closing in on a physiological cause. Contact Dermatitis 2010;62:137-149.

23 Kligman AM, Sadiq I, Zhen Y, Crosby M: Experimental studies on the nature of sensitive skin. Skin Res Technol 2006;12:217-222.

24 Farage MA: Enhancement of visual scoring of skin irritant reactions using cross-polarized light and parallel-polarized light. Contact Dermatitis 2008;58:147-155.

25 Basketter DA, Griffiths HA: A study of the relationship between susceptibility to skin stinging and skin irritation. Contact Dermatitis 1993;29:185-188.

26 Coverly J, Peters L, Whittle E, Basketter DA: Susceptibility to skin stinging, non-immunologic contact urticaria and acute skin irritation; is there a relationship? Contact Dermatitis 1998;38:90-95.

27 Lammintausta K, Maibach HI, Wilson D: Mechanisms of subjective (sensory) irritation. Propensity to non-immunologic contact urticaria and objective irritation in stingers. Derm Beruf Umwelt 1988;36:45-49.

28 Marriott M, Holmes J, Peters L, Cooper K, Rowson M, Basketter DA: The complex problem of sensitive skin. Contact Dermatitis 2005;53:93-99.

29 Green BG: Measurement of sensory irritation of the skin. Am J Contact Dermat 2000;11: 170-180.

-30 Berardesca E, Farage M, Maibach H: Sensitive skin: an overview. Int J Cosmet Sci 2013;35: 2-8.

-31 Lev-Tov H, Maibach HI: The sensitive skin syndrome. Indian J Dermatol 2012;57:419423.

- 32 Von Elm E, Altman DG, Egger M, Pocock SJ, Gøtzsche PC, Vandenbroucke JP: The Strengthening the Reporting of Observational Studies in Epidemiology (STROBE) Statement: guidelines for reporting observational studies. Bull World Health Organ 2007;85: 867-872.

-33 Quatresooz P, Piérard-Franchimont C, Piérard GE: Vulnerability of reactive skin to electric current perception - a pilot study implicating mast cells and the lymphatic microvasculature. J Cosmet Dermatol 2009;8:186-189.
34 Frosch PJ, Kligman AM: A method for appraising the stinging capacity of topically applied substances. J Soc Cosmet Chem 1977;28: 197-209.

35 Bowman JP, Floyd AK, Znaniecki A, Kligman AM, Stoudemayer T, Mills OH: The use of chemical probes to assess the facial reactivity of women, comparing their self-perception of sensitive skin. J Cosmet Sci 2000;51:267-273.

36 Querleux B, Dauchot K, Jourdain R, Bastien P, Bittoun J, Anton JL, et al: Neural basis of sensitive skin: an fMRI study. Skin Res Technol 2008; 14:454-461.

- 37 Roussaki-Schulze AV, Zafiriou E, Nikoulis D, Klimi E, Rallis E, Zintzaras E: Objective biophysical findings in patients with sensitive skin. Drugs Exp Clin Res 2005;31(suppl): 17-24.

38 Cho HJ, Chung BY, Lee HB, Kim HO, Park $\mathrm{CW}$, Lee $\mathrm{CH}$ : Quantitative study of stratum corneum ceramides contents in patients with sensitive skin. J Dermatol 2012;39:295-300.

-39 Wu Y, Wang X, Zhou Y, Tan Y, Chen D, Chen $\mathrm{Y}$, et al: Correlation between stinging, TEWL and capacitance. Skin Res Technol 2003;9:9093.

40 An S, Lee E, Kim S, Nam G, Lee H, Moon S, et al: Comparison and correlation between stinging responses to lactic acid and bioengineering parameters. Contact Dermatitis 2007; 57:158-162.

41 Distante F, Rigano L, D'Agostino R, Bonfigli A, Berardesca E: Intra- and inter-individual differences in sensitive skin. Cosmet Toiletries 2002;117:39-46.

42 Marriott M, Whittle E, Basketter DA: Facial variations in sensory responses. Contact Dermatitis 2003;49:227-231.

43 Robinson MK, Perkins MA: Evaluation of a quantitative clinical method for assessment of sensory skin irritation. Contact Dermatitis 2001;45:205-213.

44 Jourdain R, Bastien P, de Lacharriere O, Rubinstenn G: Detection thresholds of capsaicin: a new test to assess facial skin neurosensitivity. J Cosmet Sci 2005;56:153-166.

45 Clapham DE: TRP channels as cellular sensors. Nature 2003;426:517-524.

46 Dhaka A, Viswanath V, Patapoutian A: TRP ion channels and temperature sensation. Annu Rev Neurosci 2006;29:135-161.

47 Kueper T, Krohn M, Haustedt LO, Hatt H, Schmaus G, Vielhaber G: Inhibition of TRPV1 for the treatment of sensitive skin. Exp Dermatol 2010;19:980-986.

48 Loffler H, Dickel H, Kuss O, Diepgen TL, Effendy I: Characteristics of self-estimated enhanced skin susceptibility. Acta Derm Venereol 2001;81:343-346.

49 Pinto P, Rosado C, Parreirao C, Rodrigues LM: Is there any barrier impairment in sensitive skin? A quantitative analysis of sensitive skin by mathematical modeling of transepidermal water loss desorption curves. Skin Res Technol 2011;17:181-185.
50 Kim SJ, Lim SU, Won YH, An SS, Lee EY, Moon SJ, et al: The perception threshold measurement can be a useful tool for evaluation of sensitive skin. Int J Cosmet Sci 2008;30:333337.

51 Schliemann S, Antonov D, Manegold N, Elsner P: Sensory irritation caused by two organic solvents - short-time single application and repeated occlusive test in stingers and nonstingers. Contact Dermatitis 2011;65:107114.

52 De Jongh CM, Verberk MM, Withagen CE Jacobs JJ, Rustemeyer T, Kezic S: Stratum corneum cytokines and skin irritation response to sodium lauryl sulfate. Contact Dermatitis 2006;54:325-333.

53 Aramaki J, Kawana S, Effendy I, Happle R, Loffler H: Differences of skin irritation between Japanese and European women. Br J Dermatol 2002;146:1052-1056.

54 van de Vijver LPL, Boelsma E, Rausch-Goldbohm RA, Roza L: Subjective skin condition and its association with objective skin measurements. Cosmet Toiletries 2003;118:4554.

55 Nouveau-Richard S, Zhu W, Li YH, Zhang YZ, Yang FZ, Yang ZL, et al: Oily skin: specific features in Chinese women. Skin Res Technol 2007;13:43-48.

56 Kim E, Kim S, Nam GW, Lee H, Moon S, Chang I: The alkaline $\mathrm{pH}$-adapted skin barrier is disrupted severely by SLS-induced irritation. Int J Cosmet Sci 2009;31:263-269.

57 Sparavigna A, Pietro A, Setaro M: Sensitive skin: correlation with skin surface microrelief appearance. Skin Res Technol 2006;12:7-10.

-58 de Campos Dieamant G, Velazquez Pereda MDL, Eberlin S, Nogueira C, Werka RM, Queiroz MLS: Neuroimmunomodulatory compound for sensitive skin care: in vitro and clinical assessment. J Cosmet Dermatol 2008; 7:112-119.

59 Berardesca E, Abril E, Serio M, Cameli N: Effects of topical gluco-oligosaccharide and collagen tripeptide $\mathrm{F}$ in the treatment of sensitive atopic skin. Int J Cosmet Sci 2009;31:271-277.

-60 Davis JA, Visscher MO, Wickett RR, Hoath SB: Role of TNF-polymorphism-308 in neurosensory irritation. Int J Cosmet Sci 2011;33: 105-112.

-61 Lee E, An S, Lee TR, Kim HK: Development of a novel method for quantitative evaluation of sensory skin irritation inhibitors. Skin Res Technol 2009;15:464-469.

62 Lee BH, Park CK, Kim HO, Jo HJ, Park CW, Lee $\mathrm{CH}$ : The skin irritations of corrosive and non-corrosive irritants in patients with sensitive skin. Korean J Dermatol 2007;426:551559.

63 Kucharekova M, Lieffers L, van de Kerkhof PC, van der Valk PG: Dithranol irritation in psoriasis treatment: a study of 68 inpatients. J Eur Acad Dermatol Venereol 2005;19:176179 . 